\title{
Systemic and Local Corticosteroid Use Is Associated with Reduced Executive Cognition, and Mood and Anxiety Disorders
}

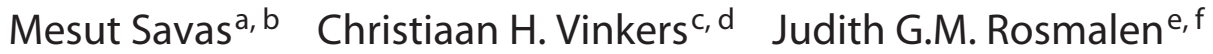 \\ Catharina A. Hartman ${ }^{f}$ Vincent L. Wester ${ }^{a, b}$ Erica L.T. van den Akker ${ }^{b, g}$ \\ Anand M. lyer $^{\mathrm{a}, \mathrm{b}}$ Bruce S. McEwen ${ }^{\mathrm{h}}$ Elisabeth F.C. van Rossum ${ }^{\mathrm{a}}$ b \\ a Department of Internal Medicine, Division of Endocrinology, Erasmus MC, University Medical Center Rotterdam, \\ Rotterdam, The Netherlands; ${ }^{b}$ Obesity Center Centrum Gezond Gewicht, Erasmus MC, University Medical \\ Center Rotterdam, Rotterdam, The Netherlands; ' Department of Psychiatry, Amsterdam UMC (Location VUmc), \\ Amsterdam, The Netherlands; ${ }^{\mathrm{d}}$ Department of Anatomy and Neurosciences, Amsterdam UMC (Location VUmc),

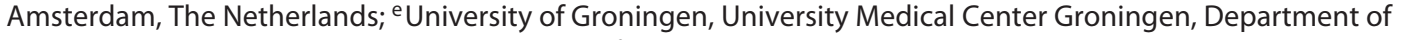 \\ Internal Medicine, Groningen, The Netherlands; ${ }^{\mathrm{f}}$ University of Groningen, University Medical Center Groningen, \\ Department of Psychiatry, Groningen, The Netherlands; ' ${ }^{9}$ Department of Pediatric Endocrinology, Erasmus MC, \\ Sophia Children's Hospital, University Medical Center Rotterdam, Rotterdam, The Netherlands; ${ }^{\text {hHarold and }}$ \\ Margaret Milliken Hatch, Laboratory of Neuroendocrinology, The Rockefeller University, New York, NY, USA
}

\section{Keywords}

Corticosteroids · Glucocorticoids · Brain · Cognition · Mood disorders · Anxiety disorders

\begin{abstract}
Background: Use of local corticosteroids, especially the inhaled types, has increasingly been associated with systemic uptake and consequent adverse effects. In this study, we assessed the associations between the use of different corticosteroid types with cognitive and neuropsychiatric adverse effects related to high glucocorticoid exposure. Methods: In 83,592 adults (mean age 44 years, 59\% women) of the general population (Lifelines Cohort Study), we analyzed the relationship between corticosteroid use with executive cognitive functioning (Ruff Figural Fluency Test), and presence of mood and anxiety disorders (Mini-International Neuropsychiatric Interview survey). We performed additional exploration for effects of physical quality of life (QoL; RAND-36), and
\end{abstract}

inflammation (high-sensitive C-reactive protein [CRP]). $\boldsymbol{R e}$ sults: Cognitive scores were lower among corticosteroid users, in particular of systemic and inhaled types, when compared to nonusers. Users of inhaled types showed lower cognitive scores irrespective of physical QoL, psychiatric disorders, and high-sensitive CRP. Overall corticosteroid use was also associated with higher likelihood for mood and anxiety disorders. Users of inhaled corticosteroids were more likely to have mood disorders (OR 1.40 [95\% Cl 1.19-1.65], $p<0.001$ ) and anxiety disorders (OR 1.19 [95\% Cl 1.06-1.33], $p=0.002$ ). These findings were independent of physical QoL. A higher likelihood for mood disorders was also found for systemic users whereas nasal and dermal corticosteroid users were more likely to have anxiety disorders. Conclusions: Commonly used local corticosteroids, in particular inhaled types, and systemic corticosteroids are associated with reduced executive cognitive functioning and a higher likelihood of mood and anxiety disorders in the general adult population.

(c) 2019 The Author(s)

Published by S. Karger AG, Basel

Elisabeth F.C. van Rossum, MD, PhD

Department of Internal Medicine, Division of Endocrinology

Erasmus MC, University Medical Center Rotterdam, Room Rg-520k, PO Box 2040

NL-3000 CA Rotterdam (The Netherlands)

E-Mail e.vanrossum@erasmusmc.nl
This aticle is licensed under the Cretive Commons Atr NonCommercial-NoDerivatives 4.0 International License (CC BYNC-ND) (http://www.karger.com/Services/OpenAccessLicense). Usage and distribution for commercial purposes as well as any distribution of modified material requires written permission. 


\section{Introduction}

Adverse effects of the glucocorticoid cortisol are usually observed in case of supraphysiological exposure as seen in patients with endogenous or exogenous Cushing's syndrome. Given the extent of cortisol action, high levels can lead to various physical as well as mental alterations. Cushing's syndrome patients, for example, develop obesity, hypertension, menstrual irregularities, and neuropsychiatric pathologies [1]. The incidence of endogenous Cushing's syndrome is extremely low with approximately 1-2 new cases per million persons annually [2]. However, the main cause of excessive glucocorticoid exposure is due to exogenous administration of drugs containing synthetic glucocorticoids [3]. These corticosteroids are one of the most prescribed drugs given their high antiinflammatory and immunomodulatory potential, and many indications. Besides, the availability of corticosteroids in many systemic and local administration formulations makes them readily feasible and convenient for clinical use. We previously showed that nearly $11 \%$ of the adults of the general population of the Netherlands was using any type of corticosteroid, which is comparable with prescription numbers in ambulatory care in the United States [4].

The common assumption is that only systemic corticosteroid variants can induce systemic adverse events, and that the effects of the local forms are generally limited to the application site. However, mounting evidence is questioning this notion. A large meta-analysis, for example, demonstrated an increased risk of adrenal insufficiency also with local corticosteroid forms [5]. Moreover, we previously demonstrated that users of systemic corticosteroids as well as the local forms, in particular of the inhaled types, were more likely to have metabolic syndrome, increased waist circumference, higher body mass index (BMI), and other adverse cardiometabolic derangements in comparison to nonusers [6]. Both increased adrenal insufficiency risk and higher likelihood of frequent corticosteroid-related metabolic effects in local corticosteroid users support the idea of systemic absorption and subsequent systemic adverse effects of local corticosteroids. In this regard, it would be reasonable to also expect effects on the brain in the case of systemic availability of these types. Despite previous studies observing cognitive impairments $[7,8]$ and psychiatric disorders [9] in endogenous Cushing's syndrome patients and systemic corticosteroid users [10], there are, to our knowledge, no large population-based studies that have investigated the associations between cognitive and psychiatric indices and use of the various local corticosteroid types. In this study, we therefore assessed the relationship of systemic and local corticosteroid use with cognition and neuropsychiatric health in the general adult population.

\section{Subjects and Methods}

\section{Study Population}

We included data of adult participants of the Lifelines research program, which is a multi-disciplinary prospective populationbased cohort study examining in a unique 3-generation design the health and health-related behaviors of 167,729 persons living in the north of The Netherlands. It employs a broad range of investigative procedures in assessing the biomedical, socio-demographic, behavioral, physical and psychological factors that contribute to the health and disease of the general population, with a special focus on multi-morbidity and complex genetics [11]. Participants were included in case of complete data regarding outcomes of the assessment for cognitive functioning, neuropsychiatric health, and physical quality of life (QoL). After exclusion of participants with inconclusive information on drug use, there were in total 83,592 subjects eligible for the current study.

\section{Corticosteroid Use}

Current drug use was assessed by questionnaire and on-site inspection of drug containers. Drugs were subsequently coded according to their corresponding WHO Anatomical Therapeutic Chemical code. We filtered users of any type of corticosteroid and grouped them as being "corticosteroid users." Drugs with only mineralocorticoid action were not included. Subclassification was made for users of only local administration forms or users of systemic corticosteroids (i.e., oral and/or parenteral) with or without any of the other types. To elaborate the associations with specific administration forms, we further classified single-type users according to their use of only systemic, inhaled, nasal, dermal or other (i.e., otological, ocular, intestinal, local-oral, hemorrhoidal, or gynaecological) types.

\section{Cognitive Functioning}

The Ruff Figural Fluency Test (RFFT) is a measure of nonverbal fluency as part of executive cognitive functioning. The test contains 5 sheets each consisting of 35 identical frames of 5-dot patterns with or without distracting elements. For each part, participants are instructed to connect 2 or more dots per frame with straight lines and to make as many as possible unique designs without falling into repetition in $1 \mathrm{~min}$ [12]. The primary outcome is the total number of unique designs (i.e., unique design score), which can range from 0 to 175 . The test was not performed in subjects who were consistently unable to properly hold a pen, had impaired vision, a score below 26 on the Mini-Mental State Examination, or had performed the test previously in another cohort study.

\section{Neuropsychiatric Assessment}

The Mini-International Neuropsychiatric Interview is a structured interview intended for diagnosing psychiatric disorders according to DSM-IV and ICD-10 diagnostic criteria [13]. Trained professionals administered the modules regarding the current diagnosis of major depressive episode, dysthymia, social phobia, 
Table 1. Characteristics of study sample

\begin{tabular}{|c|c|c|}
\hline \multirow{2}{*}{$\begin{array}{l}\text { All } \\
(n=83,592)\end{array}$} & \multicolumn{2}{|c|}{ Corticosteroid use } \\
\hline & $\begin{array}{l}\text { nonusers } \\
(n=74,591)\end{array}$ & $\begin{array}{l}\text { users } \\
(n=9,001)\end{array}$ \\
\hline
\end{tabular}

\section{Demographics}

Age, years ${ }^{\mathrm{a}}$

Sex, female ${ }^{a}$

$44.2 \pm 12.3$
$49,174(58.8)$

$24,752(29.6)$
$32,879(39.3)$
$24,424(29.2)$
$1,537(1.8)$
$7,441(8.9)$
$1.20(2.20)$

$44.1 \pm 12.3$
$43,512(58.3)$

$21,998(29.5)$
$29,491(39.5)$
$21,747(29.2)$
$1,355(1.8)$
$6,331(8.5)$
$1.20(2.10)$

$45.2 \pm 12.6$

Educational attainment ${ }^{\mathrm{a}}$

Low

Middle

High

Other

$1.20(2.20)$

$5,662(62.9)$

2,754 (30.6)

$3,388(37.6)$

2,677 (29.7)

$182(2.0)$

$1,110(12.3)$

$1.50(2.90)$

\section{Lifestyle}

Physical activity

$$
0 \text { days per week }
$$

1-4 days per week

$\geq 5$ days per week

$4,071(4.9)$
$38,632(46.2)$
$40,889(48.9)$

$38,790(46.4)$
$26,098(31.2)$
$18,704(22.4)$

$18,490(22.1)$
$41,161(49.2)$
$17,049(20.4)$
$6,892(8.3)$

$3,628(4.9)$

$443(4.9)$

$34,568(46.3)$

$4,064(45.2)$

Smoking $^{\mathrm{a}}$

Nonsmoker

Former smoker

$36,395(48.8)$

4,494 (49.9)

Current smoker

$34,428(46.2)$

$4,362(48.5)$

$23,095(31.0)$

3,003 (33.4)

$17,068(22.9)$

$1,636(18.2)$

Alcohol use ${ }^{\text {a }}$

None

$\leq 1 \mathrm{drink} /$ day

1-2 drinks/day

$16,310(21.9)$

$36,701(49.2)$

$2,180(24.2)$

$15,356(20.6)$

$4,460(49.6)$

$>2$ drinks/day

$6,224(8.3)$

$1,693(18.8)$

$668(7.4)$

\section{Cardiometabolic features}

BMI, $\mathrm{kg} / \mathrm{m}^{2 \mathrm{a}}$

$26.1 \pm 4.3$

$1,762(2.1)$

$555(0.7)$

$1,253(1.5)$

Cardiovascular diseases ${ }^{\mathrm{a}}$

Stroke ${ }^{\mathrm{a}}$

Coronary heart disease $\mathrm{a}^{\mathrm{a}}$

Ruffigural fluency test (executive cognitive functioning)

Unique designs $^{\mathrm{a}}$

MINI (psychiatric disorders)

Mood and/or anxiety disorders ${ }^{\mathrm{a}}$

Mood disorders ${ }^{\mathrm{a}}$

Anxiety disorders ${ }^{\mathrm{a}}$

RAND36 (health-related quality of life)

Physical component summary score ${ }^{\mathrm{a}}$

All values are depicted as median (interquartile range), mean $\pm \mathrm{SD}$, or numbers (percentage). BMI, body mass index; CRP, C-reactive protein. ${ }^{a}$ Significant crude differences between nonusers and users; ${ }^{b}$ data on high-sensitive CRP were available in 45,395 participants including 40,695 nonusers and 4,700 users.

generalized anxiety disorder, agoraphobia without a history of panic disorder, and lifetime presence of panic disorder with or without agoraphobia. Patients were categorized as having a mood disorder if they met the diagnostic criteria for major depressive episode or dysthymia. Anxiety disorder was deemed present in case of any of the other assessed diagnoses.

\section{Physical QoL}

Due to potential confounding by disease burden, we planned to perform subgroup analyses with stratification for health-related QoL. For this purpose, we used the outcomes of the RAND-36 questionnaire, which is a commonly used survey consisting of 36 questions related to own health status. A weighted scoring and 


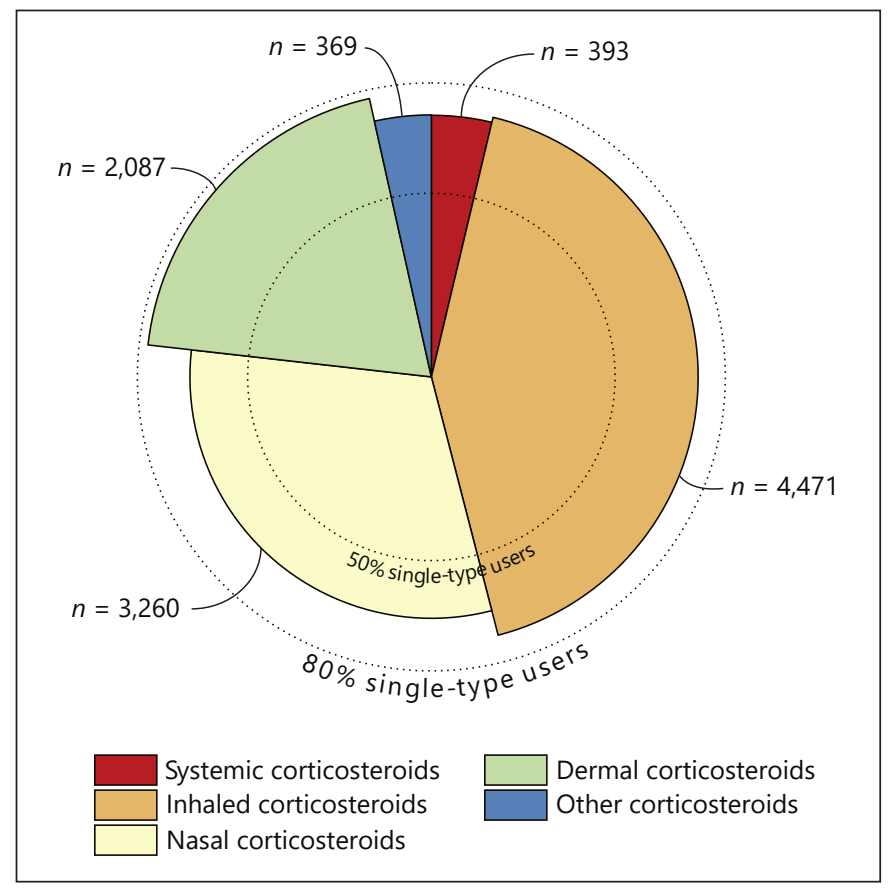

Fig. 1. Distribution of corticosteroid use in the study sample. Superimposed pie chart illustrating for each corticosteroid type the total number of users and the proportion of single-type use. The former is presented as the size of each slice and is also written in text beside. The radial length marks the percentage of users within each type who were not using any other corticosteroid types. These groups of single-type users were used to assess the associations for the specific administration forms. Single-type use was most prevalent in dermal corticosteroid users $(77.6 \%)$ while nasal corticosteroids were relatively most often combined with other types of corticosteroids.

summation of selected items results in a score between 0 and 100 for 8 different domains [14]. By calculating the Z-score for each domain using Dutch reference population [15], we computed the aggregated physical component summary score [16] as a proxy for physical QoL. A higher score corresponds to a better QoL.

\section{Covariates}

To minimize confounding, we included potential covariates based on literature, biological plausibility, and statistical significance. Besides age and sex, we assessed self-reported educational attainment classified as low (i.e., no education, primary, lower or preparatory vocational education, and lower general secondary education), middle (i.e., intermediate vocational education or apprenticeship, and higher general secondary education or pre-university secondary education), high (i.e., higher vocational education, and university), and other. The use of psychotropic drugs was evaluated by screening current drug use for antiepileptics (ATC group N03), psycholeptics (N05; e.g., antipsychotics, anxiolytics), and/or psychoanaleptics (N06; e.g., antidepressants, psychostimulants). Lifestyle factors including physical activity, smoking, and alcohol use were assessed as previously described [6]. With regard to cardiometabolic factors, we included data on BMI, and presence of cardiovascular diseases. Trained technicians measured body

Corticosteroids, Cognition, and

Psychiatric Health weight $(\mathrm{kg})$, and height $(\mathrm{cm})$. Weight and height were used to compute BMI $\left(\mathrm{kg} / \mathrm{m}^{2}\right)$. For cardiovascular diseases, subjects were asked to report if they had a past event of stroke, myocardial infarction, balloon angioplasty, and/or coronary artery bypass grafting. Any of the latter 3 conditions are also presented as coronary heart diseases in the results. Data of some covariates were missing for $<5 \%$ of the subjects, however, this was higher for physical activity (6.8\%), smoking (7.0\%), and alcohol use (9.1\%).

\section{Statistical Analysis}

Differences in descriptive characteristics between users and nonusers were analyzed with Student $t$ test or Mann-Whitney U test for continuous variables, and chi-square test for categorical data. Concerning the cognitive outcome, we performed analyses of covariance to assess differences in unique design score (RFFT analysis) between different routes of administration and for single-type users versus nonusers. We first analyzed crude differences, followed by adjustments for age, and sex. In the main model, we additionally adjusted for educational attainment, BMI, smoking, alcohol use, physical activity, cardiovascular diseases, and use of psychotropic drugs. The differences between users and nonusers in the binary outcomes for presence or absence of psychiatric disorders were assessed with logistic regression analyses. We performed similar adjustments for these analyses, and reported the crude and fully adjusted results. Interaction effects with sex and age were assessed in main analyses with complete group. With respect to disease burden, we additionally performed stratified analysis by either low ( $\leq$ median) or high ( $>$ median) physical component summary score. Moreover, given the recent finding that the unique design score is associated with anxiety and depression [17] we additionally repeated the analyses for cognitive functioning separately in participants with and without any of the assessed psychiatric disorders. IBM SPSS Statistics version 22.0.0.2 (IBM Corp., Armonk, NY, USA) was used to carry out multiple imputations for covariates with missing data, and to perform all analyses (2-sided). $p$ values below 0.050 were considered statistically significant.

\section{Sensitivity Analyses}

Since corticosteroids are generally used in the presence of inflammatory processes and given the potential effect of inflammation on mental health and functioning, we performed sensitivity analyses to evaluate the relationship between the inflammatory marker C-reactive protein (CRP) with our outcomes and whether this contributed to the differences between users and nonusers. High-sensitive CRP (hsCRP) was measured with an immuno-nephelometric assay (CardioPhase hsCRP, Siemens Healthcare Diagnostics, Marburg, Germany). Data were available of 45,395 subjects of whom $89.6 \%$ were nonusers and $10.4 \%$ users. Coefficients were assessed in the main models for both cognition and psychiatric disorders.

\section{Results}

\section{Subject Characteristics}

Characteristics of the study population as a whole and stratified for corticosteroid use are shown in Table 1. Subjects were on average 44.2 years old and $58.8 \%$ were women. Corticosteroids were being used by $10.8 \%$ of the study 


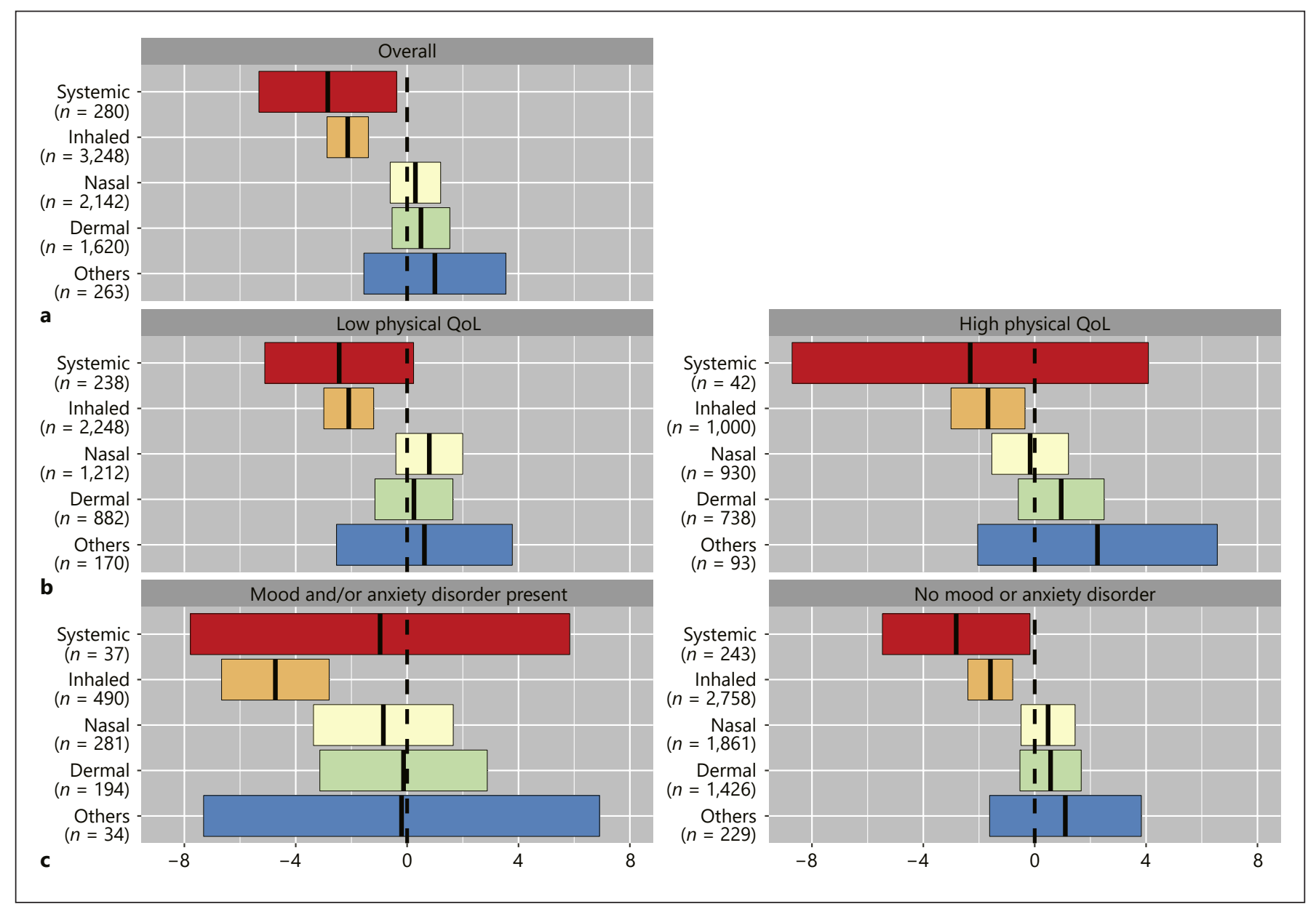

Fig. 2. Executive cognitive functioning in corticosteroid users in comparison to nonusers. Adjusted mean differences (95\% CI) in unique design score between the single-type corticosteroid users, and nonusers as reference (a). The same analyses stratified for subjects with either low or high physical component summary score as proxy for physical QoL (b), and for presence or absence of mood and/or anxiety disorders (c). Analyses are adjusted for age, sex, educational attainment, BMI, smoking, alcohol use, physical activity, cardiovascular diseases, and use of psychotropic drugs. population, which largely consisted of users of inhaled corticosteroids. The majority of users of the different administration forms were single-type users (Fig. 1). Physical QoL was higher in nonusers in comparison to users $(53.3[ \pm 7.2]$ vs. $50.3[ \pm 9.0], p<0.001)$.

\section{Corticosteroid Use and Executive Cognitive \\ Functioning}

The total unique design score was $81.3( \pm 23.3)$ in the total study population. Overall corticosteroid use was associated with a $1.6(95 \%$ CI $1.1-2.1, p<0.001)$ lower cognitive score, which remained statistically significant after full adjustments of all specified covariates. Users of only local types and users of systemic (with or without local corticosteroids) had a lower score in comparison to nonusers $(-0.9$
$[-1.4$ to -0.4$], p<0.001 ;-3.0[-5.1$ to -1.0$], p=$ 0.004 respectively). Within single-type users, only systemic corticosteroid users $(-2.9[-5.3$ to -0.4$], p=0.024)$ and inhaled corticosteroid users $(-2.1[-2.9$ to -1.4$], p<0.001)$ scored lower in unique design score when compared to non-corticosteroid users. Subgroup analyses stratified for either low or high physical QoL and for presence or absence of mood and/or anxiety disorders revealed consistently lower scores in inhaled corticosteroid users compared to nonusers (Fig. 2). With respect to other forms, only the use of systemic corticosteroids was associated with a significant lower score in subjects without mood and anxiety disorders $(-3.1[-5.8$ to -0.5$], p=0.021)$, whereas no significant differences were found for the remaining types. No interaction with sex or age was observed. 
Table 2. Association between corticosteroid use and psychiatric disorders

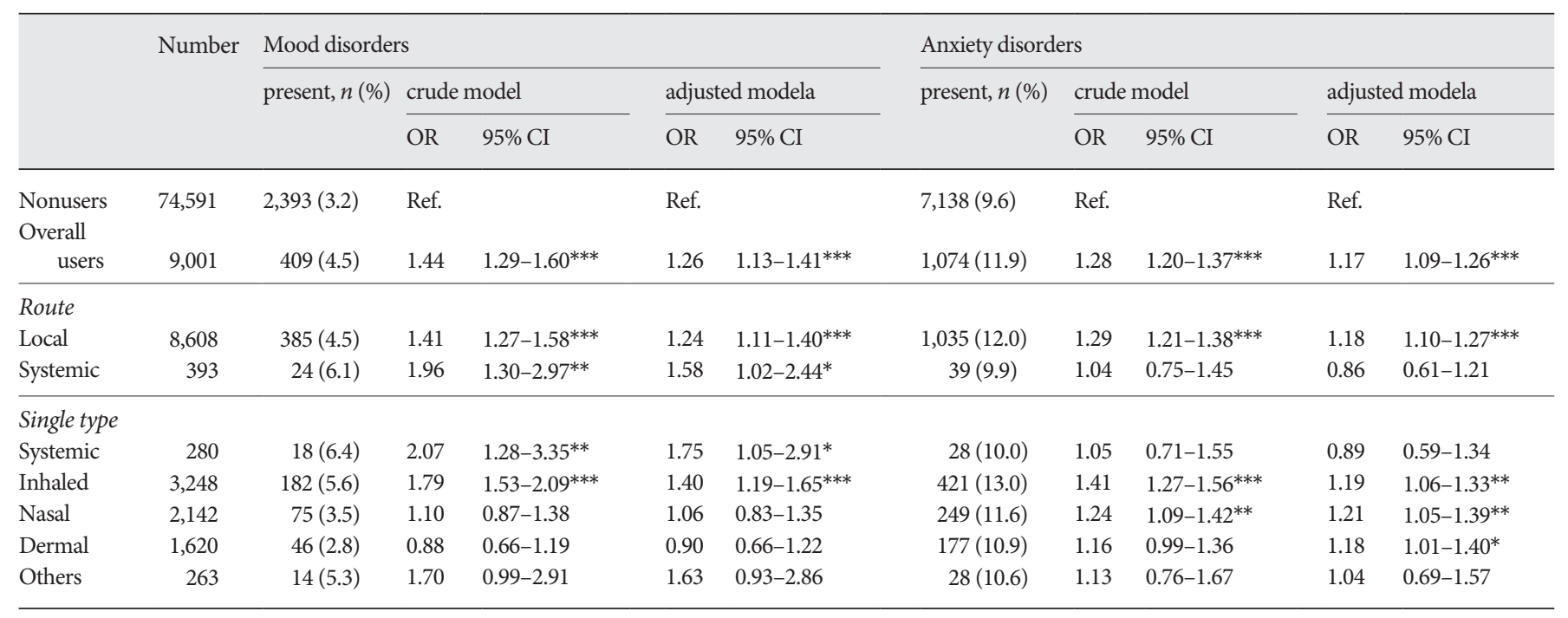

${ }^{*} p<0.050,{ }^{* *} p<0.010,{ }^{* * *} p<0.001$. The group of non-corticosteroid users is taken as reference.

a The analyses are adjusted for age, sex, educational attainment, body mass index, smoking, alcohol use, physical activity, cardiovascular diseases, and use of psychotropic drugs.

Table 3. Corticosteroid use and presence of mood and/or anxiety disorders by physical quality of life

\begin{tabular}{|c|c|c|c|c|c|c|c|c|c|c|c|c|}
\hline & \multicolumn{12}{|c|}{ Mood and/or anxiety disorders } \\
\hline & \multirow[t]{2}{*}{ number } & \multirow[t]{2}{*}{ present } & \multicolumn{2}{|c|}{ crude model } & \multicolumn{2}{|c|}{ adjusted modela } & \multirow{2}{*}{\multicolumn{2}{|c|}{ number present }} & \multicolumn{2}{|c|}{ crude model } & \multicolumn{2}{|c|}{ adjusted modela } \\
\hline & & & OR & $95 \% \mathrm{CI}$ & OR & $95 \% \mathrm{CI}$ & & & OR & $95 \% \mathrm{CI}$ & OR & $95 \% \mathrm{CI}$ \\
\hline $\begin{array}{l}\text { Nonusers } \\
\text { Overall }\end{array}$ & 36,011 & $4,740(13.2)$ & Ref. & & Ref. & & 38,580 & $3,324(8.6)$ & Ref. & & Ref. & \\
\hline \multicolumn{13}{|l|}{ Route } \\
\hline Local & 5,444 & $858(15.8)$ & 1.23 & $1.14-1.34^{* * *}$ & 1.16 & $1.06-1.26^{* * *}$ & 3,164 & $329(10.4)$ & 1.23 & $1.09-1.39^{* * *}$ & 1.21 & $1.07-1.37^{* *}$ \\
\hline Systemic & 341 & $48(14.1)$ & 1.08 & $0.80,1.47$ & 0.98 & $0.71-1.35$ & 52 & $2(3.8)$ & 0.42 & $0.10-1.74$ & 0.47 & $0.11-1.94$ \\
\hline \multicolumn{13}{|l|}{ Single type } \\
\hline Systemic & 238 & $35(14.7)$ & 1.14 & $0.79-1.63$ & 1.07 & $0.73-1.56$ & 42 & $2(4.8)$ & 0.53 & $0.13-2.20$ & 0.55 & $0.13-2.30$ \\
\hline
\end{tabular}

${ }^{*} p<0.050,{ }^{* *} p<0.010,{ }^{* * *} p<0.001$. The group of non-corticosteroid users is taken as reference. Mood and anxiety disorders are combined together due to otherwise small number of cases in users.

a The analyses are adjusted for age, sex, educational attainment, body mass index, smoking, alcohol use, physical activity, cardiovascular diseases, and use of psychotropic drugs.

Corticosteroid Use and Mood and Anxiety Disorders

Current mood and/or anxiety disorders were present in $11.1 \%$ of the total population, and were both more prevalent in corticosteroid users in comparison to nonus- ers (both $p<0.001$; Table 1). Stratification for the main route of corticosteroid administration revealed associations for local types with both mood disorders (OR 1.24 [1.11-1.40]) and anxiety disorders (OR 1.18 [1.10-1.27], 
Table 4. Differences in cognition between users and nonusers with available hsCRP data $(n=45,395)$

\begin{tabular}{|c|c|c|c|}
\hline & \multirow[t]{2}{*}{ Number } & \multicolumn{2}{|l|}{ Unique design score } \\
\hline & & model 1 & model 2 \\
\hline Nonusers & 40,695 & Ref. & Ref. \\
\hline Overall users & 4,700 & $-1.12(-1.76 \text { to }-0.48)^{* * *}$ & $-1.07(-1.71 \text { to }-0.43)^{* *}$ \\
\hline \multicolumn{4}{|l|}{ Route } \\
\hline Local & 4,497 & $-0.94(-1.59 \text { to }-0.28)^{* *}$ & $-0.89(-1.55 \text { to }-0.24)^{* *}$ \\
\hline Systemic & 203 & $-5.18(-8.10 \text { to }-2.25)^{* * *}$ & $-5.04(-7.97 \text { to }-2.12)^{* * *}$ \\
\hline \multicolumn{4}{|l|}{ Single type } \\
\hline Systemic & 153 & $-5.27(-8.64 \text { to }-1.90)^{* *}$ & $-5.13(-8.50 \text { to }-1.76)^{* *}$ \\
\hline Inhaled & 1,783 & $-2.33(-3.34 \text { to }-1.32)^{* * *}$ & $-2.28(-3.29 \text { to }-1.27)^{* * *}$ \\
\hline Nasal & 1,078 & $-0.37(-1.65$ to 0.92$)$ & $-0.33(-1.61$ to 0.96$)$ \\
\hline Dermal & 856 & $0.99(-0.45$ to 2.42$)$ & $1.00(-0.44$ to 2.44$)$ \\
\hline Others & 120 & $2.37(-1.43$ to 6.17$)$ & $2.39(-1.41$ to 6.19$)$ \\
\hline
\end{tabular}

** $p<0.010,{ }^{* * *} p<0.001$.

Adjusted mean differences (95\% CI) in total unique design score between corticosteroids users and nonusers (reference). Model 1 is adjusted for age, sex, educational attainment, body mass index, smoking, alcohol use, physical activity, cardiovascular diseases, and use of psychotropic drugs. Model 2 is additionally adjusted for hsCRP.

both $p<0.001$; Table 2). Systemic corticosteroid use was only associated with mood disorders, which was especially evident in the single-type users (OR 1.75 [1.05-2.91], $p=0.031$ ). Among users of local corticosteroids, users of only inhaled corticosteroids were more likely to have mood disorders (OR 1.40 [1.19-1.65], $p<0.001$ ) and anxiety disorders (OR 1.19 [1.06-1.33], $p=0.002$ ) in comparison to nonusers. For anxiety disorders, similar associations were present in nasal corticosteroid users (OR 1.21 [1.05-1.39], $p=0.007$ ) and dermal corticosteroid users (OR 1.18 [1.01-1.40], $p=0.043$ ). Interaction analyses for sex and age showed no significant differences. With subgroup analyses, inhaled corticosteroid use was found to be associated with increased likelihood for mood and/ or anxiety disorders in both subjects with low physical QoL (OR 1.15 [1.01-1.29], $p=0.030$ ) as well as high physical QoL (OR 1.32 [1.08-1.62], $p=0.008$; Table 3). Among users with low physical QoL, relatively high effect sizes were found for users of nasal corticosteroids and users of the group of other corticosteroids, although the difference was significant only in the former group.

\section{Sensitivity Analyses}

Corticosteroid users had in general a higher hsCRP than nonusers (median [IQR] 1.50 [2.90] vs. 1.20 [2.10] $\mathrm{mg} / \mathrm{L}, p<0.001$; Table 1 ). With regard to cognition, there was a negative association between hsCRP and unique design score $(\mathrm{B}=-0.087, \mathrm{SE}=0.022, p<0.001)$. Never- theless, the use of systemic as well as inhaled corticosteroids was persistently associated with significantly lower cognitive scores when adjusted for hsCRP (Table 4). Additional adjustment for mood and anxiety disorders did not affect these results (data not shown). There was no association between hsCRP and the presence of mood and anxiety disorders.

\section{Discussion}

In the current study, we show that use of both systemic and local corticosteroids, particularly the inhaled types, is associated with a reduced executive cognitive functioning and a higher likelihood of mood and anxiety disorders. With regard to the inhaled forms, these findings were persistent in both individuals with low and high physical QoL suggesting potential drug effects regardless of physical condition. Despite an inverse association between hsCRP levels and cognition, the use of systemic and inhaled types was independently associated with lower cognitive performance.

A reduction in executive cognitive functioning in local and systemic corticosteroid users, as found in this study, could hint on corticosteroid effects on the brain. Although multiple studies have shown an association between corticosteroid use and central nervous system disorders, the pathophysiology of exogenous corticosteroid action on 
the brain is still not well understood [18]. Corticosteroids have been described to affect various aspects of brain physiology, including selective hippocampal atrophy [19], neuronal plasticity $[20,21]$, neurotoxicity [22], and neurogenesis [23]. The hippocampus in particular is an important target of corticosteroids and strongly expresses both mineralocorticoid as well as glucocorticoid receptors [24-26]. Excess corticosteroids could lead to reversible and irreversible damage to hippocampal structure and thus contribute to cognitive impairment [26]. Another brain region that seems susceptible to corticosteroid effects is the medial prefrontal cortex. Chronic corticosterone administration [27] and behavioral stress [28] have been demonstrated to result in a reorganization of apical dendrites in pyramidal neurons of the medial prefrontal cortex in rodent models. This reorganization may have functional consequences as reflected in glucocorticoid-induced changes in cognition, working memory and stressrelated behavioral disorders [27-29]. Interestingly, the RFFT used as a measure of non-verbal fluency in the present study is especially sensitive to function [30] and dysfunction [31] of the right frontal lobe. In line with this, a previous placebo-controlled, crossover, randomized trial with healthy subjects receiving supraphysiological oral hydrocortisone found that corticosteroids indeed induced cognitive impairments which were especially related to frontal lobe dysfunction [32]. It is therefore conceivable that in case of systemic availability of local corticosteroids, in particular of the inhaled forms, these regions would also be exposed to supraphysiological glucocorticoid levels and subsequently impaired in their functioning.

We found that users of systemic and inhaled corticosteroids scored nearly 2-3 points lower on the RFFT when compared to nonusers. It is noteworthy to mention that these differences are relatively modest. Nevertheless, it is especially interesting that the outcomes point repeatedly in the same direction in all analyses for the systemic and the inhaled types. Among important contributors to RFFT score, age has consistently found to be negatively associated $[12,33]$ as was also observed in our cohort. In terms of clinical relevancy, the worse scores with inhaled and systemic corticosteroid use would on average correspond to lower scores as found with an age increase of 4.3 and 5.8 years, respectively, in our group of nonusers while controlling for other covariates.

Neuropsychiatric disorders are known to be one of the most prevalent and distressing adverse effects in users of systemic corticosteroids. Fardet and colleagues observed that approximately half of these users reported to suffer from neuropsychiatric complaints, including anxiety and

Corticosteroids, Cognition, and

Psychiatric Health depression, after they had started with corticosteroid treatment [34]. In addition, a small study with physically and mentally healthy subjects also showed behavioral changes in $75 \%$ of the participants after high-dose oral prednisone administration for 5 days [35]. Moreover, endogenous Cushing's syndrome has also frequently been linked with various psychopathologies $[9,36]$ among which mood and anxiety disorders as observed in the current study. In that sense, it would be conceivable that the inhaled types could also lead to these disorders in case of systemic absorption. This would even be more expected, given the high glucocorticoid receptor binding affinity of the frequently administered inhaled forms which is comparable to nearly 10-20 times that of dexamethasone [37]. Interestingly, the unfavorable findings regarding cognition, mood and anxiety were especially evident in users of these types. However, it should be noted that the effect sizes are relatively small. Nevertheless, these and our previous findings of higher likelihood for metabolic syndrome, a higher BMI, and other cardiometabolic alterations in users of inhaled corticosteroids [6] are in line with frequently observed features in systemic corticosteroids users and Cushing's syndrome patients. These findings are consistent with our hypothesis of systemic availability and effects of inhaled corticosteroids in which case both somatic and brain effects would be observed when exposed to supraphysiological dosages.

An important consideration in understanding the effect of corticosteroids on the brain is their penetration of the blood-brain barrier. While corticosteroids, in general, pass through cell membranes to enter the brain on account of their lipophilicity, cells comprising the bloodbrain barrier express proteins of the multidrug transporter system, which limit the access of exogenous molecules to the brain $[24,38]$. Further functional studies are essential to demonstrate the access of the various exogenous corticosteroids to different brain areas and the implications for cognitive and psychiatric functioning.

The strength of this work lies in the in-depth phenotyping, extensive assessment, and completeness for the outcome observations in large number of subjects from the general adult population. An important limitation to mention is the observational nature which hinders drawing conclusions on causality and is prone to residual confounding. Moreover, we assessed only one aspect of the various cognitive functioning domains and merely in persons with no significant impairments with the MiniMental State Examination. Finally, there were no data available on the cumulative dose exposure. However, our main findings are particularly driven by the inhaled forms 
that are conceivably used in a chronic fashion giving the underlying often chronic indications such as asthma.

\section{Conclusions}

Commonly used local corticosteroids, in particular the inhaled types, and systemic corticosteroids are associated with reduced executive cognitive functioning and a higher likelihood of mood and anxiety disorders in the general adult population. Future confirmatory studies are needed to ratify our findings and to prove temporality, while further research should also assess the associations with other cognitive processes and psychiatric disorders.

\section{Acknowledgments}

The authors wish to acknowledge the services of the Lifelines Cohort Study, the contributing research centers delivering data to Lifelines, and all the study participants.

\section{Statement of Ethics}

All participants provided written informed consent. Approval for the study protocol was obtained from the medical Ethical Committee of the University Medical Center Groningen, The Netherlands.

\section{Disclosure Statement}

The authors declare that they have no conflicts of interest to disclose.

\section{Funding Sources}

The last author (E.F.C.R.) was funded by a Vidi grant from the Netherlands Organisation for Scientific Research NWO (grant number: 91716453) and an Erasmus MC research fellowship. The Lifelines Biobank initiative has been made possible by funds from Fonds Economische Structuurversterking, Samenwerkingsverband Noord Nederland and Ruimtelijk Economisch Programma.

\section{References}

1 Nieman LK. Cushing's syndrome: update on signs, symptoms and biochemical screening. Eur J Endocrinol. 2015 Oct;173(4):M33-8.

2 Lindholm J, Juul S, Jørgensen JO, Astrup J, Bjerre P, Feldt-Rasmussen U, et al. Incidence and late prognosis of cushing's syndrome: a population-based study. J Clin Endocrinol Metab. 2001 Jan;86(1):117-23.

3 Nieman LK, Biller BM, Findling JW, NewellPrice J, Savage MO, Stewart PM, et al. The diagnosis of cushing's syndrome: an endocrine society clinical practice guideline. J Clin Endocrinol Metab. 2008 May;93(5):1526-40.

4 Raofi S, Schappert SM. Medication therapy in ambulatory medical care: United States, 200304. Vital Health Stat 13. 2006 Dec;(163):1-40.

5 Broersen LH, Pereira AM, Jørgensen JO, Dekkers OM. Adrenal insufficiency in corticosteroids use: systematic review and metaanalysis. J Clin Endocrinol Metab. 2015 Jun; 100(6):2171-80.

6 Savas M, Muka T, Wester VL, van den Akker EL, Visser JA, Braunstahl GJ, et al. Associations between systemic and local corticosteroid use with metabolic syndrome and body mass index. J Clin Endocrinol Metab. 2017 Oct;102(10):3765-74.

7 Forget H, Lacroix A, Somma M, Cohen H. Cognitive decline in patients with Cushing's syndrome. J Int Neuropsychol Soc. 2000 Jan; 6(1):20-9.

8 Bourdeau I, Bard C, Forget H, Boulanger Y, Cohen H, Lacroix A. Cognitive function and cerebral assessment in patients who have Cushing's syndrome [ix.]. Endocrinol Metab Clin North Am. 2005 Jun;34(2):357-69.
9 Sonino N, Fava GA. Psychiatric disorders associated with Cushing's syndrome. Epidemiology, pathophysiology and treatment. CNS Drugs. 2001;15(5):361-73.

10 Judd LL, Schettler PJ, Brown ES, Wolkowitz OM, Sternberg EM, Bender BG, et al. Adverse consequences of glucocorticoid medication: psychological, cognitive, and behavioral effects. Am J Psychiatry. 2014 Oct;171(10):1045-51.

11 Stolk RP, Rosmalen JG, Postma DS, de Boer RA, Navis G, Slaets JP, et al. Universal risk factors for multifactorial diseases: LifeLines: a three-generation population-based study. Eur J Epidemiol. 2008;23(1):67-74.

12 Ruff RM, Light RH, Evans RW. The ruff figural fluency test - a normative study with adults. Dev Neuropsychol. 1987;3(1):37-51.

13 Sheehan DV, Lecrubier Y, Sheehan KH, Amorim P, Janavs J, Weiller E, et al. The Mini-International Neuropsychiatric Interview (M.I.N.I.): the development and validation of a structured diagnostic psychiatric interview for DSM-IV and ICD-10. J Clin Psychiatry. 1998;59 Suppl 20:22-33.

14 VanderZee KI, Sanderman R, Heyink JW, de Haes H. Psychometric qualities of the RAND 36-Item Health Survey 1.0: a multidimensional measure of general health status. Int $\mathrm{J}$ Behav Med. 1996;3(2):104-22.

15 Aaronson NK, Muller M, Cohen PD, EssinkBot ML, Fekkes M, Sanderman R, et al. Translation, validation, and norming of the Dutch language version of the SF-36 Health Survey in community and chronic disease populations. J Clin Epidemiol. 1998 Nov;51(11): 1055-68.
16 Ware JE, Kosinski M, Keller SD. Sf-36 physical and mental component summary measures: A user's manual. Boston (MA): The Health Institute, New England Medical Center; 1994.

17 Gulpers B, Lugtenburg A, Zuidersma M, Verhey FR, Voshaar RC. Anxiety disorders and figural fluency: A measure of executive function. J Affect Disord. 2018 Jul;234:38-44.

18 Ciriaco M, Ventrice P, Russo G, Scicchitano M, Mazzitello G, Scicchitano F, et al. Corticosteroid-related central nervous system side effects. J Pharmacol Pharmacother. 2013 Dec; 4(5 Suppl 1):S94-8.

19 McEwen BS. Possible mechanisms for atrophy of the human hippocampus. Mol Psychiatry. 1997 May;2(3):255-62.

20 Woolley CS, Gould E, McEwen BS. Exposure to excess glucocorticoids alters dendritic morphology of adult hippocampal pyramidal neurons. Brain Res. 1990 Oct;531(1-2):225-31.

21 Watanabe Y, Gould E, McEwen BS. Stress induces atrophy of apical dendrites of hippocampal CA3 pyramidal neurons. Brain Res. 1992 Aug;588(2):341-5.

22 Sapolsky RM. The possibility of neurotoxicity in the hippocampus in major depression: a primer on neuron death. Biol Psychiatry. 2000 Oct;48(8):755-65.

23 Odaka H, Adachi N, Numakawa T. Impact of glucocorticoid on neurogenesis. Neural Regen Res. 2017 Jul;12(7):1028-35.

24 De Kloet ER, Vreugdenhil E, Oitzl MS, Joëls M. Brain corticosteroid receptor balance in health and disease. Endocr Rev. 1998 Jun; 19(3):269-301. 
25 de Kloet ER, Oitzl MS, Joëls M. Functional implications of brain corticosteroid receptor diversity. Cell Mol Neurobiol. 1993 Aug;13(4): 433-55.

26 Brown ES, Rush AJ, McEwen BS. Hippocampal remodeling and damage by corticosteroids: implications for mood disorders. Neuropsychopharmacology. 1999 Oct;21(4):474-84.

27 Wellman CL. Dendritic reorganization in pyramidal neurons in medial prefrontal cortex after chronic corticosterone administration. J Neurobiol. 2001 Nov;49(3):245-53.

28 Radley JJ, Sisti HM, Hao J, Rocher AB, McCall T, Hof PR, et al. Chronic behavioral stress induces apical dendritic reorganization in pyramidal neurons of the medial prefrontal cortex. Neuroscience. 2004;125(1):1-6.

29 McKlveen JM, Myers B, Herman JP. The medial prefrontal cortex: coordinator of autonomic, neuroendocrine and behavioural responses to stress. J Neuroendocrinol. 2015 Jun;27(6):446-56.
30 Foster PS, Williamson JB, Harrison DW. The Ruff Figural Fluency Test: heightened right frontal lobe delta activity as a function of performance. Arch Clin Neuropsychol. 2005 Jun; 20(4):427-34.

31 Ruff RM, Allen CC, Farrow CE, Niemann H, Wylie T. Figural fluency: differential impairment in patients with left versus right frontal lobe lesions. Arch Clin Neuropsychol. 1994 Jan;9(1):41-55.

32 Young AH, Sahakian BJ, Robbins TW, Cowen PJ. The effects of chronic administration of hydrocortisone on cognitive function in normal male volunteers. Psychopharmacology (Berl). 1999 Aug;145(3):260-6.

33 Izaks GJ, Joosten H, Koerts J, Gansevoort RT, Slaets JP. Reference data for the Ruff Figural Fluency Test stratified by age and educational level. PLoS One. 2011 Feb;6(2):e17045.

34 Fardet L, Flahault A, Kettaneh A, Tiev KP, Généreau T, Tolédano $\mathrm{C}$, et al. Corticosteroid-induced clinical adverse events: frequency, risk factors and patient's opinion. Br J Dermatol. 2007 Jul;157(1):142-8.
35 Wolkowitz OM, Rubinow D, Doran AR, Breier A, Berrettini WH, Kling MA, et al. Prednisone effects on neurochemistry and behavior. Preliminary findings. Arch Gen Psychiatry. 1990 Oct;47(10):963-8.

36 Pereira AM, Tiemensma J, Romijn JA. Neuropsychiatric disorders in Cushing's syndrome. Neuroendocrinology. 2010;92 Suppl 1:65-70.

37 Daley-Yates PT. Inhaled corticosteroids: potency, dose equivalence and therapeutic index. Br J Clin Pharmacol. 2015 Sep;80(3): 372-80.

38 Meijer OC, de Lange EC, Breimer DD, de Boer AG, Workel JO, de Kloet ER. Penetration of dexamethasone into brain glucocorticoid targets is enhanced in mdr1A P-glycoprotein knockout mice. Endocrinology. 1998 Apr;139(4):1789-93. 